\title{
The Position of Clinical Pharmacists in Delivering Advanced Pharmacy Practice Education and Services: Short Communication
}

\author{
Alebachew M*, Tileku M, Beyene A, Berihun D, Asefa T, Ayalneh B and Fayissa M \\ Department of Pharmacology and Clinical Pharmacy, School of Pharmacy, College of Health Sciences, Addis Ababa University, Addis Ababa, Ethiopia
}

*Corresponding author: Alebachew M, Department of Pharmacology and Clinical Pharmacy, School of Pharmacy, College of Health Sciences, Addis Ababa University, Addis Ababa, Ethiopia, Tel: +251-912-648527; E-mail: minwoldu@gmail.com

Received date: May 12, 2016; Accepted date: June 15, 2016; Published date: June 20, 2016

Copyright: (C) 2016 Alebachew M, et al. This is an open-access article distributed under the terms of the Creative Commons Attribution License, which permits unrestricted use, distribution, and reproduction in any medium, provided the original author and source are credited.

\begin{abstract}
The pharmacist's role in health systems continues to evolve from a product focus to a patient-centered care model ensuring the safe and effective use of medications in all practice settings. The scope of pharmacy practice now includes patient-centered care with all the cognitive functions of counseling, providing drug information and monitoring drug therapy, as well as technical aspects of pharmaceutical services, including medicines supply management. Clinical Pharmacy consist of all the services accomplished by pharmacists practicing in hospitals, community pharmacies, nursing homes, home-based care services, clinics and any other setting wherever medicines are prescribed and used. Advanced pharmacy practice should be handled and delivered by facilities where high standards of pharmaceutical care and instruction are available and preceptors and educators should be actively engaged in the delivery of high-quality pharmaceutical care, and spend a majority of their time providing pharmaceutical care in their facility.
\end{abstract}

Keywords: Pharmacy practice; Clinical pharmacy; Advanced pharmacy practice

\section{Introduction}

\section{The paradigm shift in pharmacy services}

The pharmacist's role in health systems continues to evolve from a product focus to a patient-centered care model ensuring the safe and effective use of medications in all practice settings. As pharmacy practice evolves, the education and postgraduate training of pharmacists must ensure that pharmacists are adequately prepared to assume advanced practice roles in direct patient care $[1,2]$. The introduction of experiential learning in pharmacy practice curricula is therefore very mandatory as it provides the students with practical experience in various aspects of the profession of pharmacy [3]. Current pharmacy practice is considerably more diverse than what has been previously reported in terms of scope of practice and practice setting [4]. It is therefore timely to consider professional pharmacy practice and the way in which we can define and progress the well accepted concept of 'advanced pharmacy practice' [5]. A pharmacist preceptor (PharmD and clinical pharmacists) directs the majority of practice experiences. The objective of the current short communication is to make readers familiar with the position of clinical pharmacists in provision of pharmacy practice courses and services and to show them that these two names (pharmacy practice \& clinical pharmacy) are two faces of same coin and hence can be used interchangeably unless and otherwise specified.

\section{Scope of practice of clinical pharmacy}

Education, training, experience, and awareness of practice standards and trends help create the practice model vision [1]. The scope of pharmacy practice now includes patient-centred care with all the cognitive functions of counseling, providing drug information and monitoring drug therapy, as well as technical aspects of pharmaceutical services, including medicines supply management [6]. Clinical pharmacy services to support the national medicines policy includes: access, equity and continuum of care, decision support tools, drug use evaluation, patient information and education programs, clinical risk management, training and education and research [7].

Clinical pharmacists should be involved in activities directed to individual patients and more broadly to support the objectives of the national medicines policy, especially its quality use of medicines (QUM) arm. Procedures for clinical pharmacy services for individual patients include Medication Action Plan [Interpretation of PatientSpecific Data, Identification of Clinical Problems, Establishment of Therapeutic Goals, Evaluation of Therapeutic Options, Individualization of Therapy, and Monitoring of Patient Outcomes] [8].

Clinical pharmacy practice is the practice of pharmacy as part of a multidisciplinary healthcare team directed at achieving QUM. This may include participation in the management of individual patients; application of the best available evidence in daily clinical practice; and contribution of clinical knowledge and skills to the healthcare team [8]. The primary focus of community pharmacy as component of pharmacy practice is to provide professional care to patients, supported by safe and effective medication management and medication information, comprehensive warfarin counseling, smoking cessation counseling, MUR-medicine use reviews, free emergency contraception counseling and dispensing, flu vaccination campaigns, waste management and DUMP (Dispose Unwanted Medicines Programme) and medication counselling for patients initiated on medicines for mild to moderate depression in which all require an indepth clinical pharmacy knowledge [7]. 


\section{Pharmacy practice vs. clinical pharmacy}

The "Practice of Pharmacy" means the interpretation, evaluation, and implementation of Medical Orders; the Dispensing of Prescription Drug Orders; participation in Drug and Device selection; Drug Administration; Drug Regimen Review; the Practice of Telepharmacy within and across state lines; Drug or Drug-related research; the provision of Patient Counselling; the provision of those acts or services necessary to provide Pharmacist Care in all areas of patient care, including Primary Care and Collaborative Pharmacy Practice; and the responsibility for Compounding and Labelling of Drugs and Devices (except Labelling by a Manufacturer, Repackaging, or Distributor of Non-Prescription Drugs and commercially packaged Legend Drugs and Devices), proper and safe storage of Drugs and Devices, and maintenance of required records. The practice of pharmacy also includes continually optimizing patient safety and quality of services through effective use of emerging technologies and competency-based training $[9,10]$.

Clinical Pharmacy is a health science discipline in which pharmacists provide patient care that optimizes medication therapy and promotes health, wellness, and disease prevention. To achieve desired therapeutic goals, the clinical pharmacist applies evidencebased therapeutic guidelines, evolving sciences, emerging technologies, and relevant legal, ethical, social, cultural, economic, and professional principles [11]. The clinical pharmacist is trained in clinical pharmacy practice and comprehensive medication management to include, but not limited to clinical pharmacokinetics, therapeutics, and clinical pharmacology [12].

Clinical Pharmacy consist of all the services accomplished by pharmacists practicing in hospitals, community pharmacies, nursing homes, home-based care services, clinics and any other setting wherever medicines are prescribed and used. The term "clinical" does not necessarily suggest an action implemented only in a hospital settings [13]. A clinical pharmacist has the unique mix of knowledge, skills, and abilities in addition to education, training and experience to function under a scope of practice. Furthermore, the clinical pharmacist has a current unrestricted pharmacist license and is in good standing with the pharmacist's licensing body [12].

The University Health System Consortium (CHC) work force concluded that institutions need a practice model to support basic medication management services on a consistent basis for all patients and specialized services for specific patients depending on their clinical situations. Technology may help achieve this goal, but a welltrained workforce and an appropriate model design are critical for success [1].

\section{The global view of pharmacy practice and clinical pharmacy}

In U.S. and India, pharmacy practice mean a postgraduate course designed to make students familiar with patient care rotations, institutional practice, community practice and ambulatory care practices [14,15]. According to Introductory Pharmacy Practice Experience (IPPE) and Advanced Pharmacy Practice Experience (APPE) Manual of the University of Georgia, the purpose of the experiential training portion of the curriculum is to provide pharmacy students with practical experience in various aspects of the profession of pharmacy. A pharmacist preceptor (Pharm.D and clinical pharmacists) directs the majority of practice experiences. APPEs are designed to provide students the opportunity to focus on clinical aspects of pharmacy practice. These experiences usually involve direct patient care in a specific clinical area (e.g., cardiology, oncology, pediatrics, etc.). However, some experiences may not have direct patient care (e.g., drug information, pharmaceutical industry, research, etc.) [16].

According to Queens University Belfast, advance pharmacy practice is a 12 module over 54 month period course and aims to make pharmacists to be independent prescribers in health system facilities. These modules are focusing in hospital pharmacy, clinical medicine, disease management, advanced therapeutics, development of leadership skills; drug distribution and control systems ethical practices and research $[17,18]$.

According to University of Houston, college of pharmacy, students taking advanced pharmacy practice shall able to perform the functions of a pharmacist in a hospital setting including dispensing Function: Inpatient area, manufacturing, compounding, repackaging, controlled substances, and investigational drugs. Management Function: operations, purchasing, inventory control. Educational Function: drug information, healthcare professional education, patient education and Pharmaceutical Care Function: monitoring, evaluating drug therapy, emergency pharmacy services, communication [19].

\section{The situations in Ethiopia}

In Ethiopia-Jimma University, took the lead in clinical pharmacy using the advantages of its unique experiential learning practice sites and its community-based approach to learning, which allows students to train in the university's teaching hospital and local training health centres. The Clinical Pharmacy and Pharmacy Practice (CPPP) course team is lead by clinical pharmacists and provides more than $40 \%$ of the major courses required for BPharm program and owns all courses for the MSc program in Clinical pharmacy [20,21].

At Addis Ababa University (AAU), the Advanced Pharmacy Practice course of the MSc in Pharmacy practice program has been designed for students to make students familiar with the advanced pharmacy practice services in hospitals and community pharmacies. Under the hospital pharmacy chapter the following areas are targeted: overview of organization and structure, basic and specialized hospital pharmacy services; hospital drug policy: drug and therapeutics committee, formulary and guidelines, research \& ethics committee, infection control committee, patient safety/medication safety. hospital pharmacy management: Staff, finance, policy \& planning, infrastructural requirements, drug distribution system, pharmaceutical care, drug therapy needs of a patient, drug therapy problems, pharmaceutical care process. Developing a clinical approach in clinical pharmacy practice: Clinical information: Clinical notes, records and charts, pharmaceutical interventions, understanding clinical laboratory tests, screening patients for medication problems, reviewing medication histories, ethics and confidentiality. Communicating information: Developing questioning, explaining and listening skills, non-verbal communication, undertaking patient consultations. Medicines information: Searching for and evaluating medicines information, Evidence-based Medicine and Medication therapy management in which all require in-depth clinical pharmacy knowledge [22].

Under the community pharmacy chapter also the following points were given focus: Overview of organization, administration, drug supply management; dispensing, prescription and OTC medicines, responding to symptoms, dispensing of herbal/alternative medicines, medication therapy management that has been addressed in the earlier 
Page 3 of 5

international experiences can be again addressed by clinical pharmacists [22].

\section{Qualification requirement for clinical pharmacy practice courses}

According to ACCP commentary, Postgraduate Training-PGY1 Residency Training should have to be handled by all full-time clinical pharmacy practice faculty, as well as all adjunct clinical faculty with direct patient care responsibilities and all actively precepting students, complete a PGY1 residency or possess equivalent experience [23]. It is essential that advanced pharmacy course should be provided in facilities where high standards of pharmaceutical care and instruction are available. Therefore, Patient Care Advanced Practice Experience preceptors and sites must meet certain qualifications criteria. The clinical preceptor should be a clinical scientist with expertise in the area of pharmD, clinical pharmacy/pharmacy practice, which may be exemplified by: receiver of fellowship training, a graduate degree, and/or equivalent experiences [24] and be actively engaged in the delivery of high-quality pharmaceutical care, and spend a majority of their time providing pharmaceutical care in their facility but also will commit sufficient time to education [19].

\section{Peculiar advanced pharmacy practice services}

Articles were searched in a pubmed database using a key term "(((clinical pharmacists) AND advanced pharmacy practice) AND education) AND services" without restriction for year of publication and total of 66 articles were identified. From these articles, the following services and educational activities were summarized as shown in the Table 1. Hence, the professional activities of clinical pharmacists in not limited to the activities listed on the tables.

\begin{tabular}{|c|c|c|c|}
\hline Department & Type of service & Core purpose & References \\
\hline $\begin{array}{l}\text { Teaching Hospitals and } \\
\text { research institutes }\end{array}$ & $\begin{array}{l}\text { Hospital pharmacy practice, teaching activities, } \\
\text { drug supply management, drug selection, } \\
\text { quantification, cost minimization and expiry } \\
\text { drug disposal services }\end{array}$ & $\begin{array}{l}\text { Bring changes in the professional structure of pharmacy including } \\
\text { education and training, specialization, career structure and the } \\
\text { roles of pharmacy technicians }\end{array}$ & [25-33] \\
\hline $\begin{array}{l}\text { Emergency Medicine } \\
(\mathrm{EM})\end{array}$ & $\begin{array}{l}\text { Pharmacy Education, critical care, therapy } \\
\text { management and monitoring }\end{array}$ & $\begin{array}{l}\text { Determine prevalence and characteristics of EM-related education } \\
\text { opportunities for pharmacy students and residents. }\end{array}$ & [34] \\
\hline $\begin{array}{l}\text { Community } \\
\text { pharmacies }\end{array}$ & $\begin{array}{l}\text { Oral chemotherapy services, wellness services, } \\
\text { cognitive memory screening, psychotherapy, } \\
\text { pharmacogenetic testing, health education, } \\
\text { concordance, counselling, medication therapy } \\
\text { management (MTM), follow-up and referral } \\
\text { services }\end{array}$ & $\begin{array}{l}\text { Determine educational and training opportunities for community } \\
\text { pharmacists, thereby improve patient-centred experiences that } \\
\text { supplement their confidence, knowledge, and skill in providing } \\
\text { advanced pharmacy services }\end{array}$ & [35-46] \\
\hline Surgical department & Cardiopulmonary resuscitation (CPR) & $\begin{array}{l}\text { Determine pharmacist participation on CPR teams in health care } \\
\text { delivery organizations }\end{array}$ & {$[47,48]$} \\
\hline Regulatory scrutiny & Drug Pricing & $\begin{array}{l}\text { Evaluate and monitor drug pricing through the use key metrics on } \\
\text { cost savings achieved, maintenance costs, and other aspects of } \\
\text { program involvement }\end{array}$ & [49] \\
\hline In-patient & Pharmaceutical care & $\begin{array}{l}\text { Provision of pharmaceutical care, identification of drug therapy } \\
\text { problems, prevention of adverse drug reactions and monitoring of } \\
\text { drug therapy management }\end{array}$ & {$[48,50,51]$} \\
\hline Out-patient department & Ambulatory care, patient education & $\begin{array}{l}\text { Assertively advancing ambulatory care practice, to achieve the } \\
\text { national priorities of improving patient care, adherence, patient } \\
\text { health, and affordability of care }\end{array}$ & {$[48,52,53]$} \\
\hline Pediatric department & Pediatric care & Provision of advanced pediatric care & {$[48,54]$} \\
\hline $\begin{array}{lr}\text { Intensive care units } \\
\text { and } \\
\text { department }\end{array}$ & Palliative care services & $\begin{array}{l}\text { Introducing the concept of 'advanced practice roles' in pharmacy } \\
\text { within the new integrated regionalized palliative care service }\end{array}$ & {$[48,55,56]$} \\
\hline
\end{tabular}

Table 1: Type of services with respect to its purpose.

\section{Conclusions}

Clinical pharmacy practice has developed internationally to expand the role of a pharmacist well beyond the traditional roles of compounding and supplying drugs to roles more directly in caring for patients and providing medication consultation to staff. This area of practice is at its infant age in Ethiopia. Advanced pharmacy practice should be handled and delivered by facilities where high standards of pharmaceutical care and instruction are available and preceptors and educators should be actively engaged in the delivery of high-quality pharmaceutical care, and spend a majority of their time providing pharmaceutical care in their facility.

\section{References}

1. UHC (2010) Pharmacy Practice Model for Academic Medical Centers. In: Consortium UH. Oak Brook.

2. ACCP (2012) Desired Professional Development Pathways for Clinical Pharmacists. American College of Clinical Pharmacy 33: e34-e42. 
3. Legesse M, Teklay G, Fikadu D, Demeke B (2012) Clerkship guideline for undergraduate pharmacy students. In: Mekelle, Mekelle University College of Health Sciences Department of Pharmacy.

4. Giberson S, CDR Yoder S, CDR P Lee M (2011) Improving Patient and Health System Outcomes through Advanced Pharmacy Practice. In: A Report to the US Surgeon General, RADM.

5. Recognition of advanced pharmacy practice in Australia (2010) In: Competency Standards Review Steering Committee RPSGB.

6. WHO (2006) Developing pharmacy practice: A focus on patient care. In: Standards DoMPa Geneva, Switzerland FIP.

7. West J, Amey J, Knapton C, Illing S (2012) Clinical pharmacy in general practice Midlands Health Network.

8. SHPA (2005) Standards of Practice for Clinical Pharmacy. J Pharm Pract Res 35: 122-146.

9. Council on Credentialing in Pharmacy (2009) Scope of Contemporary Pharmacy Practice: Roles, Responsibilities, and Functions of Pharmacists and Pharmacy Technicians. In: Pharmacy TCoCi, Washington, DC.

10. Pharmacy NBO (2008) Pharmacy NAoBo: Model State Pharmacy Act and Model Rules of the 3 .

11. ACCP (2008) The Definition of Clinical Pharmacy. Pharmacotherapy 28 816-817.

12. Veterans Health Administration (2015) Clinical pharmacy services. In: Affairs DoV. Washington.

13. Implementation of Advances and Challenges in Clinical Pharmacy (2015) In: 3rd International Conference on Clinical Pharmacy. Atlanta, USA.

14. Toronto UO (2015) Advanced Pharmacy Practice Experience. In: Toronto Uo.

15. WSOP (2015) Advanced pharmacy practice experiences (appe) manual.

16. Pharmacy TUoGCo (2014) Introductory Pharmacy Practice Experience (IPPE) and Advanced Pharmacy Practice Experience (APPE) Manual.

17. Belfast QU (2013) MSc in Advanced Pharmacy Practice with Independent Prescribing.

18. TTUHSC SOP (2012) Introduction to Pharmacy Practice. In: Amarillo.

19. University of Houston (2014) Advanced hospital pharmacy practice experience course description. In: UoHCo.

20. AAU (2009) Pharmacy course syllubus. School of pharmacy, University J.

21. Mekonnen AB, Yesuf EA, Odegard PS, Wega SS (2013) Implementing ward based clinical pharmacy services in an Ethiopian University Hospital. Pharmacy Practice 11: 51-57.

22. AAU (2010) Pharmacy practice course syllubus. School of Pharmacy.

23. Janet PE, Brian LE, Douglas CA, Jr, Mason HB, Chan A, et al. (2013) Minimum Qualifications for Clinical Pharmacy Practice Faculty. In: ACoC.

24. ACCP (2004) Guidelines for Clinical Research Fellowship Training Programs. In: The ACCP Board of Regents.

25. Auta A, Maz J, Strickland-Hodge B (2015) Perceived facilitators to change in hospital pharmacy practice in England. International Journal of Clinical Pharmacy 37: 1068-1075.

26. Delgado O, Kernan WP, Knoer SJ (2014) Advancing the pharmacy practice model in a community teaching hospital by expanding student rotations. American Journal of Health-System Pharmacy AJHP: Official Journal of the American Society of Health-System Pharmacists 71: 1871-1876.

27. Woolley AB, Berds C, Edwards RA, Copeland D, Divall MV (2013) Potential cost avoidance of pharmacy students' patient care activities during advanced pharmacy practice experiences. Am J Pharm Educ 77: 164.

28. Assemi M, Corelli RL, Ambrose PJ (2011) Development needs of volunteer pharmacy practice preceptors. Am J Pharm Educ 75: 10.

29. Keresztes JM (2010) Education...A must in all levels of pharmacy practice. The Annals of Pharmacotherapy 44: 1826-1828.

30. Rickles NM, Brown TA, McGivney MS, Snyder ME, White KA (2010) Adherence: A review of education, research, practice, and policy in the United States. Pharm Pract (Granada) 8: 1-17.
31. Slazak EM, Zurick GM (2009) Practice-based learning experience to develop residents as clinical faculty members. American Journal of Health-system Pharmacy AJHP: Official Journal of the American Society of Health-System Pharmacists 66: 1224-1227.

32. Kheir N, Zaidan M, Younes H, El Hajj M, Wilbur K, et al. (2008) Pharmacy education and practice in 13 Middle Eastern countries. Am J Pharm Educ 72: 133

33. Gong SD, Millares M, VanRiper KB (1992) Drug information pharmacists at health-care facilities, universities, and pharmaceutical companies. American Journal of Hospital Pharmacy 49: 1121-1130.

34. Vollman KE, Adams CB, Shah MN, Acquisto NM (2015) Survey of Emergency Medicine Pharmacy Education Opportunities for Students and Residents. Hospital Pharmacy 50: 690-699.

35. Butt F, Ream E (2016) Implementing oral chemotherapy services in community pharmacies: a qualitative study of chemotherapy nurses' and pharmacists' views. The International Journal of Pharmacy Practice 24: 149-159.

36. Sriram D, McManus A, Emmerton L, Jiwa M (2015) Will Australians pay for health care advice from a community pharmacist? A video vignette study. Research in Social and Administrative Pharmacy RSAP 11: 579-583.

37. Rickles NM, Skelton JB, Davis J, Hopson J (2014) Cognitive memory screening and referral program in community pharmacies in the United States. International Journal of Clinical Pharmacy 36: 360-367.

38. Warshany K, Sherrill CH, Cavanaugh J, Ives TJ, Shilliday BB (2014) Medicare annual wellness visits conducted by a pharmacist in an internal medicine clinic. American journal of health-system pharmacy AJHP: Official Journal of the American Society of Health-System Pharmacists 71: 44-49.

39. McKee BD, Larose-Pierre M, Rappa LR (2015) A survey of community pharmacists and final-year student pharmacists and their perception of psychotherapeutic agents. Journal of Pharmacy Practice 28: 166-174.

40. O'Connor SK, Ferreri SP, Michaels NM, Chater RW, Viera AJ, et al. (2012) Making pharmacogenetic testing a reality in a community pharmacy. JAPHA 52: e259-e265.

41. Hardin HC, Hall AM, Roane TE, Mistry R (2012) An advanced pharmacy practice experience in a student-staffed medication therapy management call center. Am J Pharm Educ 76: 110.

42. Bosse N, Machado M, Mistry A (2012) Efficacy of an over-the-counter intervention follow-up program in community pharmacies. JAPHA 52: 535-540.

43. Hata M, Klotz R, Sylvies R, Hess K, Schwartzman E, et al. (2012) Medication therapy management services provided by student pharmacists. Am J Pharm Educ 76: 51.

44. Mandt I, Horn AM, Ekedahl A, Granas AG (2010) Community pharmacists' prescription intervention practices-exploring variations in practice in Norwegian pharmacies. RSAP 6: 6-17.

45. Blake KB, Madhavan SS (2010) Perceived barriers to provision of medication therapy management services (MTMS) and the likelihood of a pharmacist to work in a pharmacy that provides MTMS. The Annals of Pharmacotherapy 44: 424-431.

46. Salter C (2010) Compliance and concordance during domiciliary medication review involving pharmacists and older people. Sociology of Health and Illness 32: 21-36.

47. Bolt J, Semchuk W, Loewen P, Bell A, Strugari C (2015) A Canadian Survey of Pharmacist Participation during Cardiopulmonary Resuscitation. The Canadian Journal of Hospital Pharmacy 68: 290-295.

48. Grindrod KA, Marra CA, Colley L, Tsuyuki RT, Lynd LD (2010) Pharmacists' preferences for providing patient-centered services: a discrete choice experiment to guide health policy. The Annals of Pharmacotherapy 44: 1554-1564.

49. Karralli R, Tipton J, Dumitru D, Scholz L, Masilamani S (2015) Development of a metrics dashboard for monitoring involvement in the 340B Drug Pricing Program. American Journal of Health-System Pharmacy. AJHP: Official Journal of the American Society of HealthSystem Pharmacists 72: 1489-1495. 
Citation: Alebachew M, Tileku M, Beyene A, Berihun D, Asefa T, et al. (2016) The Position of Clinical Pharmacists in Delivering Advanced Pharmacy Practice Education and Services: Short Communication. Clin Exp Pharmacol 6: 216. doi:10.4172/2161-1459.1000216

Page 5 of 5

50. Lancaster JW, Douglass MA, Gonyeau MJ, Wong A, Woolley AB, et al (2013) Providers' perceptions of student pharmacists on inpatient genera medicine practice experiences. Am J Pharm Educ 77: 26.

51. Rovers J, Miller MJ, Koenigsfeld C, Haack S, Hegge K, et al. (2011) A guided interview process to improve student pharmacists' identification of drug therapy problems. Am J Pharm Educ 75: 16.

52. Helling DK, Johnson SG (2014) Defining and advancing ambulatory care pharmacy practice: it is time to lengthen our stride. American journal of health-system pharmacy: AJHP: Official Journal of the American Society of Health-System Pharmacists 71: 1348-1356.

53. Grice GR, Tiemeier A, Hurd P, Berry TM, Voorhees M, et al. (2014) Student use of health literacy tools to improve patient understanding and medication adherence. The Consultant pharmacist: The Journal of the American Society of Consultant Pharmacists 29: 240-253.
54. Stacey SR, Coombes I, Wainwright C, Cardiff L, Whitfield K (2015) What does advanced practice mean to Australian pediatric pharmacists? A focus group study. The International Journal of Pharmacy Practice 23: 141-149.

55. Swetenham K, Rowett D, Stephenson D (2014) Clinical networks influencing policy and practice: the establishment of advanced practice pharmacist roles for specialist palliative care services in South Australia. Australian Health Review: Australian Hospital Association 38: 238-241.

56. Walker KA, Scarpaci L, McPherson ML (2010) Fifty reasons to love your palliative care pharmacist. The American Journal of Hospice \& Palliative Care 27: 511-513. 